\title{
Effect of Aminophyllin and Dexamethasone on Secretion of Pulmonary Surfactant in Fetal Rabbits
}

\author{
ANTHONY J. CORBET, ${ }^{(22)}$ PHYLLIS FLAX, CHERYL ALSTON, AND ARNOLD J. RUDOLPH
}

Department of Pediatrics, Baylor College of Medicine, Houston, Texas, USA

\begin{abstract}
Summary
Aminophyllin, dexamethasone, or saline was injected into 27.5day fetal rabbits $2.5 \mathrm{hr}$ before sacrifice, after which static pressurevolume curves with air were performed. In further similar experiments the lungs were lavaged with physiologic saline which was analyzed for total phospholipid content. There were no changes in total lung capacity (TLC) induced with either aminophyllin or dexamethasone. The lungs of fetal rabbits injected with saline retained $44 \%$ TLC $( \pm 3 \mathrm{SE})$ after deflation to $10 \mathrm{~cm} \mathrm{H}_{2} \mathrm{O}$ transpulmonary pressure compared with $48 \%$ TLC $( \pm 3$ SE) in those injected with dexamethasone, a difference which was not statistically significant. In contrast, the lungs of fetal rabbits injected with aminophyllin retained $53 \%$ TLC $( \pm 2 \mathrm{SE})$ after deflation to 10 $\mathrm{cm} \mathrm{H}_{2} \mathrm{O}$ pressure, a significant increase when compared with saline controls $(P<0.01)$. There were no changes in lung weight or lung water. These results were interpreted to mean that aminophyllin decreased surface tension and augmented secretion of pulmonary surfactant. This was supporied by finding significantly increased total phospholipid recovered in the lung lavage fluid of fetal rabbits injected with aminophyllin, $62 \mu \mathrm{g} / \mathrm{g}$ dry lung weight ( $\pm 6 \mathrm{SE}$ ) compared with $32 \mu \mathrm{g} / \mathrm{g}$ dry lung weight $( \pm 3 \mathrm{SE})$ in saline controls $(P<0.05)$. Phospholipid recovered from dexamethasoneinjected fetal rabbits was not significantly increased, $38 \mu \mathrm{g} / \mathrm{g}$ dry lung weight $( \pm 4 \mathrm{SE})$.
\end{abstract}

\section{Speculation}

Although other explanations cannot be excluded, the effect of aminophyllin in promoting secretion of surfactant is consistent with proposals that the secretory process is under control of cAMP.

Hyaline membrane disease (HMD) in premature newborn infants is due to a deficiency of surfactant in the air spaces of lung. Although the frequency of HMD increases with decreasing gestational age, it has been suggested that enough surfactant is present in the parenchyma of lung by 30 weeks of gestation to line the air spaces up to 40 times (14). An important step, however, is secretion of the surfactant material from storage sites within the granular pneumocyte. Because the concentration of lecithin in amniotic fluid increases sharply, the secretory process is thought to be greatly enhanced in the normal human fetus at about 35 weeks of gestation (10). Although this process may be under control of glucocorticoid hormones (8), attention has also been directed towards the role of $\beta$-adrenergic catecholamines (20). It has been proposed that the latter augment the secretory process by stimulating adenyl cyclase, which would result in increased levels of cAMP (17). Another way to increase cAMP is to inhibit the enzyme CAMP phosphodiesterase, which is responsible for further metabolism and hence inactivation of cAMP (3). We have injected fetal rabbits with aminophyllin (Searle Laboratories), a competitive inhibitor of phosphodiesterase, and dexamethasone (Merck,
Sharp and Dohme), a glucocorticoid hormone, and after a comparatively short interval examined the lungs for evidence of increases in surfactant secretion.

\section{MATERIALS AND METHODS}

Twenty-five pregnant White New Zealand rabbits (Rich-glo Experimental Animal Farm, El Campo, TX) of 27.5 days of gestation (6) were used in these experiments. Each doe was anesthetized by inhalation of methoxyflurane in a mixture of air and oxygen. The uterus was exposed by midline abdominal incision under semisterile operating conditions.

Each fetus in each litter was given an ip injection (6) with either aminophyllin $(5 \mathrm{mg})$ in a volume of $0.1 \mathrm{ml}$, dexamethasone (1 mg) in $0.1 \mathrm{ml}$ saline, or with $0.1 \mathrm{ml}$ saline alone. The abdominal incision was closed with a continuous suture and the doe allowed to recover. After $2.5 \mathrm{hr}$ the abdomen was reopened under anesthesia and the fetal rabbits delivered by hysterotomy. They were killed immediately by ip injection of pentobarbital $(20 \mathrm{mg})$. Fetal rabbits showing no sign of movement after delivery and before sacrifice were discarded.

After weighing each newborn rabbit, a tracheostomy tube was ligated in place (Clay Adams, PE-50). All fetal rabbits in each litter then had performed either a lung static pressure-volume curve with air followed by measurements of wet and dry lung weight, or they had a lung lavage with saline followed by measurement of dry lung weight. The methods used for obtaining the pressure-volume curves with air and measuring wet and dry lung weight have been previously described (6).

The volume of air in the lung at $30 \mathrm{~cm} \mathrm{H}_{2} \mathrm{O}$ inflation pressure was defined as total lung capacity (TLC). The deflation curves were analyzed by expressing the volume of air remaining in the lung at each pressure as a percentage of TLC (\%TLC). Special attention was given to the value at $10 \mathrm{~cm} \mathrm{H}_{2} \mathrm{O}$ pressure (\%TLC10). The volume of air, expressed as \%TLC, evacuated between 5 and $0 \mathrm{~cm} \mathrm{H}_{2} \mathrm{O}$ (5-0\%TLC) was also calculated. The ratio of wet lung weight to body weight (LW/BW) and the lung water content $\left(\% \mathrm{H}_{2} \mathrm{O}\right)$ were obtained from measurements of wet and dry lung weight.

Lung lavage was performed in individual fetal rabbits five times using physiologic saline. At the beginning of each cycle the syringe contained $2.0 \mathrm{ml}$ fresh saline, but the volume injected was usually $1.0-1.5 \mathrm{ml}$, based on $1.0 \mathrm{ml} / 20 \mathrm{~g}$ body weight. The fluid from five cycles in each fetal rabbit was combined, but if more than a total of $0.5 \mathrm{ml}$ did not return (recovery less than 90\%), the fetal rabbit was discarded. Each sample of fluid $(9.5-10.0 \mathrm{ml})$ was centrifuged at $1000 \times \mathrm{g}$ for $5 \mathrm{~min}$ at $0^{\circ}$ to remove cells and debris (11). Then $8 \mathrm{ml}$ chloroform-methanol $(2: 1)$ was added to $2 \mathrm{ml}$ supernatant, vortexed, and centrifuged with $1000 \times \mathrm{g}$ for $15 \mathrm{~min}$ at $0^{\circ}$ (9). After removal of the top methanol layer and interfacial pellicle, washing of the bottom chloroform layer was performed with $0.4 \mathrm{ml}$ water and repeat centrifugation. After removal of the top water layer, 1$\mathrm{ml}$ samples of chloroform were analyzed in triplicate for phospho- 
rus by the method of Chen et al. (4). The values for phosphorus were converted to total phospholipid by multiplying by 25 (9), and then standardized for dry lung weight in grams. Preliminary experiments showed that 5 lavages obtained better than $90 \%$ of the phospholipid phosphorus obtained with 15 lavages, and that the last 5 lavages contained negligible amounts of phospholipid phosphorus indicating that recovery was complete.

In the statistical analysis of results only litters with at least five data points were included, which in practice meant that data points from each litter always numbered 5-10. The mean values reported $( \pm S E)$ represent the mean for all individual fetal rabbits in a particular experimental group. In assessing the significance of differences with Student's t-test, however, the number used was the number of litters, and the mean used was the mean of the average values for each litter (1). The latter value always corresponded closely with the reported mean for all individual fetal rabbits.

\section{RESULTS}

The number of litters, fetal rabbits, deaths, and failed procedures, together with the number of pressure-volume curves and lung lavage samples included in each experimental series, is given in Table 1. There was an increase in deaths, possibly attributable to the drug in litters injected with aminophyllin but not with dexamethasone.

The lungs of all fetal rabbits having pressure-volume curves appeared fully expanded with air before deflation. The TLC for lungs of fetal rabbits injected with aminophyllin or dexamethasone was similar to the TLC of saline-injected controls (Table 2). On deflation to low transpulmonary pressures the lungs of fetal rabbits injected with aminophyllin (Fig. 1), but not those of fetal rabbits injected with dexamethasone (Fig. 2), retained significantly more air expressed as \%TLC than the lungs of saline-injected controls. The greatest difference was reflected in the values for \%TLC-10 (Table 2). Whereas the slope on deflation below $10-15 \mathrm{~cm} \mathrm{H}_{2} \mathrm{O}$ in lungs of fetal rabbits injected with saline or dexamethasone tended to decrease progressively (Fig. 2) in the lungs of fetal rabbits injected with aminophyllin, the slope on deflation below 10-15 $\mathrm{cm} \mathrm{H}_{2} \mathrm{O}$ remained constant (Fig. 1). The values for 5-0 \% TLC were significantly higher in the lungs of fetal rabbits injected with aminophyllin (Table 2). There was no changes in LW/BW or \% $\mathrm{H}_{2} \mathrm{O}$ (Table 2).

Significantly more phospholipid was recovered by lavage from the lungs of fetal rabbits injected with aminophyllin than from saline controls (Table 2), but this was not the case in fetal rabbits injected with dexamethasone.

No significant differences in behavior compared to saline controls were observed in does whose litters were injected with dexamethasone or aminophyllin.

\section{DISCUSSION}

These experiments demonstrate that aminophyllin, but not dexamethasone, injected into 27.5-day fetal rabbits $2.5 \mathrm{hr}$ before sacrifice, produced significantly increased retention of air when

Table 1. Experimental population having pressure-volume (P-V) curves with air or lung lavage with saline ${ }^{1}$

\begin{tabular}{ccccccc}
\hline & Litters & Fetuses & Deaths & Discards ${ }^{2}$ & $\begin{array}{c}\text { P-V } \\
\text { curves }\end{array}$ & Lavages \\
\hline Saline & 5 & 40 & 0 & 2 & 38 & \\
& 4 & 33 & 0 & 1 & & 32 \\
$\begin{array}{c}\text { Dexameth- } \\
\text { asone }\end{array}$ & 3 & 26 & 0 & 1 & 25 & \\
Amino- & 5 & 31 & 0 & 0 & & 31 \\
phyllin & 4 & 38 & 0 & 2 & 36 & \\
\hline
\end{tabular}

\footnotetext{
${ }^{1}$ Litters of less than five fetal rabbits were not included.

${ }^{2}$ Discarded for technical failure in lavage or $\mathrm{P}-\mathrm{V}$ curve.
}

Table 2. Data in fetal rabbits injected with saline, dexamethasone, or aminophyllin ${ }^{1}$

\begin{tabular}{lccc}
\hline & Saline & Dexamethasone & Aminophyllin \\
\hline TLC/g (ml) & 2.0 & 2.3 & 1.7 \\
& \pm 0.1 & \pm 0.1 & \pm 0.1 \\
$\%$ TLC-10 & 44 & 48 & $53^{2}$ \\
& \pm 2 & \pm 3 & \pm 3 \\
$5-0 \%$ TLC & 12 & 14 & $19^{3}$ \\
& \pm 1 & \pm 1 & \pm 1 \\
\% $\mathrm{H}_{2} \mathrm{O}$ & 89 & 87 & 89 \\
& \pm 0 & \pm 0 & \pm 1 \\
$\mathrm{LW} / \mathrm{BW}$ & 0.027 & 0.026 & 0.026 \\
& \pm 0.001 & \pm 0.001 & \pm 0.001 \\
$\mathrm{PL} / \mathrm{g}(\mu \mathrm{g})^{4}$ & 32 & 38 & $62^{3}$ \\
& \pm 3 & \pm 4 & \pm 6 \\
\hline
\end{tabular}

\footnotetext{
${ }^{1}$ Values are mean \pm SE for all individual fetal rabbits compared with saline controls.

${ }^{2} P<0.01$.

${ }^{3} P<0.05$ (see Materials and Methods).

${ }^{4}$ Phospholipid per gram dry lung weight.
}

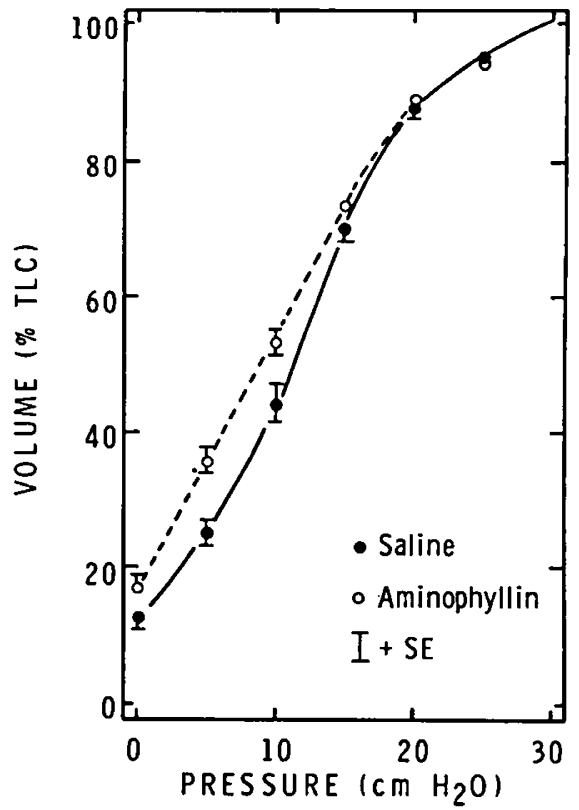

Fig. 1. Mean data for static pressure-volume curves with air in 27.5-day fetal rabbits injected with aminophyllin or saline $2.5 \mathrm{hr}$ before sacrifice. Differences are significant at $10 \mathrm{~cm} \mathrm{H}_{2} \mathrm{O}(P<0.01)$.

lungs were deflated. Increased airway closure with air-trapping can be excluded because there was no decrease in the volume of air evacuated at very low transpulmonary pressures (5-0 \% TLC) when most airway closure would be expected (19). The most likely explanation for the change induced with aminophyllin is a marked reduction in surface tension, since retention of air at relatively low pressures under static conditions is almost entirely dependent on surface rather than tissue compliance in fetal rabbit lungs (6). This interpretation is supported by the observation that the deflation slope below $10 \mathrm{~cm} \mathrm{H} \mathrm{H}_{2} \mathrm{O}$ in fetal rabbits injected with aminophyllin remained constant (Fig. 1), whereas it decreased in those injected with saline or dexamethasone (Fig. 2), an important difference also reflected in the significantly higher values for 5-0 \% TLC in fetal rabbits injected with aminophyllin (Table 2). Such a change in shape of the deflation curve is believed to reflect a decrease in surface tension (6) induced with aminophyllin. 


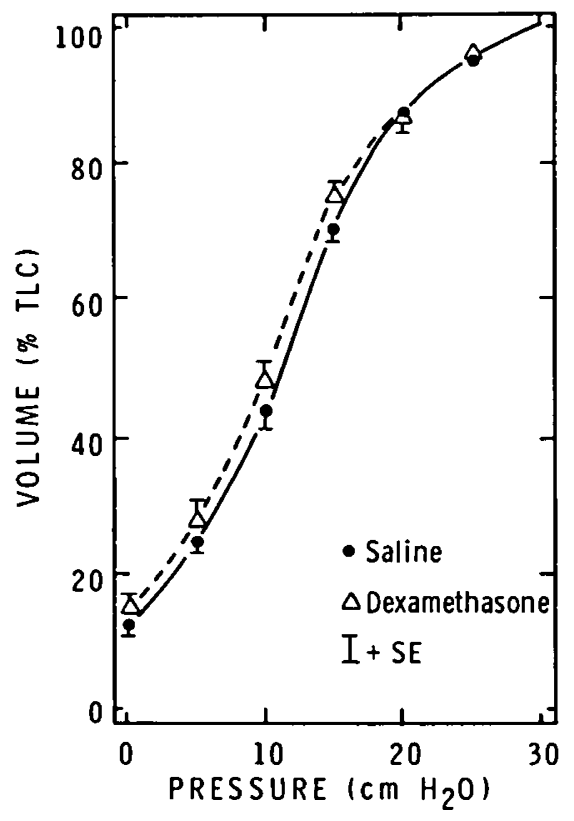

Fig. 2. Mean data for static pressure-volume curves with air in 27.5-day fetal rabbits injected with dexamethasone or saline $2.5 \mathrm{hr}$ before sacrifice. Differences are not statistically significant.

To explain decreased surface tension it is reasonable to postulate reduction in a surfactant inhibitor such as water (16) or protein (18). In the lungs of fetal rabbits injected with aminophyllin the water content remained the same as in controls (Table 2), but it is not possible to exclude a change in lung proteins. Nevertheless, the most likely explanation for decreased surface tension with aminophyllin is increased secretion of surfactant into the air spaces of lung, presumably from the granular pneumocytes.

The major component of the pulmonary surfactant is phospholipid, although about $20 \%$ is composed of neutral lipid and protein (5), not included in measurements of totai phospholipid. Whereas many phospholipids possess at least some surface activity, the most active fraction is thought to be dipalmityl phosphatidylcholine (12), which makes up an increasing proportion of the total phospholipid in lung lavage fluid with advancing gestation (9). The proportion of surface-active phospholipid in lung lavage fluid is significantly higher than in lung parenchyma (13). Although the measurement of total phospholipid in lung lavage fluid is a relatively crude index, there is good reason to believe it is representative of an important component of the pulmonary surfactant. Furthermore, presumably because total phospholipid in lung lavage is interrelated with parenchymal phospholipid, measurements of total phospholipid in lung tissue correlate well with other indices of surface tension in the lung such as the pressure-volume diagram (2). Thus, the observation that aminophyllin produced a significant increase in the total phospholipid recovered by lung lavage strongly supports the conclusion that decreased surface tension, as demonstrated with the static pressure-volume curve, was due to increased secretion of pulmonary surfactant.

It has been suggested that dexamethasone may play a role inducing not only synthesis but also secretion of surfactant in fetal lambs, but the effect was of delayed onset and seen only after at least 1.5 days of infusion with dexamethasone (15). Evidence consistently suggests that glucocorticoids take several days to produce an effect on surfactant production in the lung (7). This was reflected in the observation that unlike aminophyllin, dexamethasone given to fetal rabbits $2.5 \mathrm{hr}$ before sacrifice had no significant effect on the static pressure-volume curve or on the recovery of phospholipid by lung lavage (Table 2 ). Thus it would appear unlikely that dexamethasone has a direct effect upon the secretory process.

\section{CONCLUSION}

Pressure-volume curves with air were used to assess surface tension in the lungs of fetal rabbits at 27.5 days of gestation. The lungs of fetal rabbits injected with aminophyllin $2.5 \mathrm{hr}$ before sacrifice retained more air on deflation than lungs of fetal rabbits injected only with saline. The interpretation that this was due to reduced surface tension associated with augmented surfactant secretion was supported by finding increased phospholipid recovered in lung lavage from fetal rabbits injected with aminophyllin. In contrast, dexamethasone injected in 27.5-day fetal rabbits for $2.5 \mathrm{hr}$ under similar conditions produced no significant change in surface tension or phospholipid recovered by lung lavage.

\section{REFERENCES AND NOTES}

1. Abbey, H., and Howard, E.: Statistical procedure in developmental studies on species with multiple offspring. Develop. Psychobiol., 6: 329 (1973).

2. Brumley, G. W., Chernick, V., Hodson, W. A., Normand, C., Fenner, A., and Avery, M. E.: Correlations of mechanical stability, morphology, pulmonary surfactant and phospholipid content in the developing lamb lung. J. Clin. Invest., 46: 863 (1967).

3. Butcher, R. W., and Sutherland, E. W.: Adenosine 3',5'-monophosphate in biological materials. J. Biol. Chem., 237: 1244 (1962).

4. Chen, P. S., Toribara, T. Y., and Warner, H.: Microdetermination of phosphorus. Anal. Chem., 28: 1756 (1956).

5. Clements, J. A.: Composition and properties of pulmonary surfactant. In: C. A. Villee, D. B. Villee, and J. Zuckerman: Respiratory Distress Syndrome, (Academic Press., New York, 1973).

6. Corbet, A. J. S., Flax, P., and Rudolph, A. J.: Reduced surface tension in lungs of fetal rabbits injected with pilocarpine. J. Appl. Physiol., 41: 7 (1976).

7. Farrell, P. M., and Avery, M. E.: Hyaline membrane disease. Amer. Rev. Resp. Dis., 111: 657 (1975).

8. Farrell, P. M., and Zachman, R. D.: Induction of choline phosphotransferase and lecithin synthesis by corticosteroids. Science, 179: 297 (1973).

9. Fujiwara, T., Adams, F. H., Sipos, S., and El-Salawy, A.: "Alveolar" and whole lung phospholipids of the developing fetal lamb lung. Amer. J. Physiol., 215: 375 (1968).

10. Gluck, L., and Kulovich, M. V.: Lecithin-sphingomyelin ratios in amniotic fluid in normal and abnormal pregnancy. Amer. J. Obstet. Gynecol., 115: 535 (1973).

11. Gluck, L., Motoyama, E. K., Smits, H. L., and Kulovich, M. V.: The biochemical development of surface activity in mammalian lung. Pediat. Res., I: 237 (1967).

12. Klaus, M., Clements, J. A., and Havel, R. J.: Composition of surface active material isolated from beef lung. Proc. Nat. Acad. Sci. U. S. A., 47: 1858 (1961).

13. Morgan, T. E., Finley, T. N., and Fialkow, H.: Comparison of the composition and surface activity of "alveolar" and whole lung lipids in the dog. Biochim. Biophys. Acta, 106: 403 (1965).

14. Platzker, A., Clements, J. A., and Tooley, W.: Surfactant development in the human fetal lung [Abstr.]. Clin. Res., 19: 232 (1971).

15. Platzker, A. C. G., Kitterman, J. A., Mescher, E. J., Clements, J. A., and Tooley, W. T.: Surfactant in the lung and tracheal fluid of the fetal lamb and acceleration of its appearance by dexamethasone. Pediatrics, 56: 554 (1975).

16. Redding, R. A., Arai, T., Douglas, W., Tsurutani, H., and Overs, J.: Early changes in the lungs of rats exposed to 70\% oxygen. J. Appl. Physicl., 38: 136 (1975).

17. Taeusch, H. W., Wyszogrodski, I., Wang, N. S., and Avery, M. E.: Pulmonary pressure-volume relationships in premature fetal and newborn rabbits. J. Appl. Physiol., 37: 809 (1974).

18. Taylor, F. B., and Abrams, M. E.: Effect of surface active lipoprotein on clotting and fibrinolysis, and of fibrinogen on surface tension of surface active lipoprotein. Amer. J. Med., 40: 346 (1966).

19. Woolcock, A. J., Macklem, P. T., Hogg, J. C., Wilson, N. J., Nadel, A. J., Frank, N. R., and Brain, J.: Effect of vagal stimulation on central and peripheral airways in dogs. J. Appl. Physiol.; 6: 806 (1969).

20. Wyszogrodski, I., Taeusch, H. W., and Avery, M. E.: Isoxsuprine-induced alterations of pulmonary pressure-volume relationships in premature rabbits. Amer. J. Obstet. Gynecol., 119: 1107 (1974).

21. This research was supported by Grant RR-05425 from the PHS USPHS General Research Support.

22. Requests for reprints should be addressed to: Dr. Anthony Corbet, Department of Pediatrics, Baylor College of Medicine, Texas Medical Center, Houston, TX 77030 (USA).

23. Received for publication May 23, 1977.

24. Accepted for publication October 10, 1977. 